\title{
Measured and Modeled Residue Dynamics of Famoxadone and Oxathiapiprolin in Tomato Fields
}

\author{
Feng, Xiaoxiao; Wang, Kai; Pan, Lixiang; Xu, Tianheng; Zhang, Hongyan; Fantke, Peter
}

Published in:

Journal of Agricultural and Food Chemistry

Link to article, DOI:

10.1021/acs.jafc.8b02056

Publication date:

2018

Document Version

Peer reviewed version

Link back to DTU Orbit

Citation (APA):

Feng, X., Wang, K., Pan, L., Xu, T., Zhang, H., \& Fantke, P. (2018). Measured and Modeled Residue Dynamics of Famoxadone and Oxathiapiprolin in Tomato Fields. Journal of Agricultural and Food Chemistry, 66(32), 84898495. https://doi.org/10.1021/acs.jafc.8b02056

\section{General rights}

Copyright and moral rights for the publications made accessible in the public portal are retained by the authors and/or other copyright owners and it is a condition of accessing publications that users recognise and abide by the legal requirements associated with these rights.

- Users may download and print one copy of any publication from the public portal for the purpose of private study or research.

- You may not further distribute the material or use it for any profit-making activity or commercial gain

- You may freely distribute the URL identifying the publication in the public portal 
1 Measured and modeled residue dynamics of famoxadone and oxathiapiprolin in tomato fields

2

3 Xiaoxiao Feng, ${ }^{\dagger}$ Kai Wang, ${ }^{\dagger}$ Lixiang Pan,${ }^{\dagger}$ Tianheng Xu, ${ }^{\dagger}$ Hongyan Zhang $^{* \dagger}$ and Peter Fantke ${ }^{* I}$

$4 \quad$ College of Science, China Agricultural University, Beijing 100193, P R China

5 Institute of Inorganic and Analytical Chemistry, Johannes Gutenberg University of Mainz,

6

Duesbergweg 10-14, 55128 Mainz, Germany

7 "Quantitative Sustainability Assessment Division, Department of Management Engineering, Technical

8 University of Denmark, Bygningstorvet 116, 2800 Kgs. Lyngby, Denmark

9 *Corresponding Authors:

10

*Tel: (+86) 010-62733219. E-mail: hongyan@cau.edu.cn

11

*Tel: (+45) 452544 52. E-mail: pefan@dtu.dk

12 
14 ABSTRACT: A reliable analytical method for the simultaneous determination of famoxadone and

oxathiapiprolin dissipation kinetics, as well as the metabolites of oxathiapiprolin (IN-E8S72 and IN-WR791) in tomato and soil was developed. We studied the dissipation of famoxadone and oxathiapiprolin in tomatoes grown using different kinetic curves in the area of Beijing in 2015 and 2016. Our results show that the most suitable model for two fungicides in 2015 and 2016 was first-order kinetic and second-order kinetic with the half-lives 3.4 to 5.2 and 2.4 to 3.0 days, respectively. In addition, we applied the dynamic plant uptake model dynamiCROP and combined it with results from the field experiments to investigate the uptake and translocation of famoxadone and oxathiapiprolin in the soil-tomato environment. Modeled and measured results of two years fitted well with $\mathrm{R}^{2}$ values ranging from 0.8072 to 0.9221 . The fractions of famoxadone and oxathiapiprolin applied during tomato cultivation that are eventually ingested by humans via residues in crop harvest were finally evaluated and found to be in the range of one part per thousand, that is one gram intake per kg applied. 


\section{INTRODUCTION}

With a global production of 172 million tons in 2014 and an increase of 35\% between 2004 and

2014, tomato is one of the most important vegetable crops in regard to human consumption. ${ }^{1}$ The fruits rich in nutrients can be eaten uncooked or cooked and processed as e.g. ketchup, juice, and puree. ${ }^{2}$ In order to increase yield of tomatoes and to control unwanted pests and diseases, pesticides are continuously and intensively applied in tomato agroecosystems. ${ }^{3}$ However, humans may inhale and ingest pesticides that reach non-target areas through wind drift, surface runoff, leaching, and bystander. ${ }^{4}$ More importantly, pesticide residues in vegetables through consumption may lead to higher exposure for human. ${ }^{5,6}$ In particular, tomatoes are usually less processed before consumed. Maximum Residue Limits (MRLs) have been established by several national monitoring organizations (e.g., European Commission and Codex Alimentarius Commission) to reduce human exposure dose to pesticides and ensure that the consumption of crop products is within acceptable risk levels. However,

MRLs of major pesticides are often established based on limits of determination (LOD) and acceptable daily intake (ADI). The understanding of pesticide distribution in the environment and potential toxicity-related effects on humans, in contrast, are usually not considered. Due to the extreme complexity of consistently characterizing the crop-environment system including the consideration of crop characteristics, substance properties and environmental properties, it is a challenging task to fully understand the behavior of pesticides in agricultural fields and subsequent exposures and impacts on humans and the environment. ${ }^{7,8}$

A number of studies on the dissipation of pesticides in the crops have been reported. ${ }^{9-13}$ However, most of these studies only focus on the pesticide residue values in the environment (e.g., soil and water) and the behavior of pesticides, such as pesticide uptake and translocation processes in the plants grown 
for human or animal consumption, has not been explained. Besides, pesticides dissipation evaluation is measured by analytical methods which often limited by the time involved, high costs and analytical detection limits. ${ }^{14}$ In order to address these gaps, a variety of models have been developed to predict dissipation trend of pesticide in crops and provide deeper insights into specific plant-environment systems since the 1990s. A detailed review was reported by Fantke et al. in $2011 .{ }^{15}$ Some of these models were developed only for pesticide uptake and transfer through roots and tubers, ${ }^{16,17}$ while some only focused on atmospheric deposition onto leaves. ${ }^{18}$ Roots, stem, leaves, fruits, and soil were all considered as compartments in studies by Rein et al. ${ }^{19}$ and Legind et al. ${ }^{20}$ However, the parameter of air was not included in their models.

Recently, a dynamic plant-uptake model, named dynamiCROP, was developed by Fantke et al. 8,15,21 The dynamiCROP model includes all compartments (environmental and plant compartments) and pathways (pesticide initial mass distribution, bioaccumulation, and translocation) for assessing pesticide uptake into crops, and subsequent human health and ecosystem health exposures and impacts. More importantly, the model includes nine major food crops (wheat, rice, barley, maize, tomato, apple, potato, lettuce, and passion fruit) consumed by humans in daily life and has been successfully applied to predict some pesticide residues in wheat, rice, potato, apple, passion fruit, lettuces and tomatoes. ${ }^{8,15,22-25}$

Famoxadone and oxathiapiprolin were two fungicide widely used in tomatoes. ${ }^{26-28}$ Especially for oxathiapiprolin, discovered and developed by DuPont in July 2012, is the first piperidinyl thiazole isoxazoline fungicide. ${ }^{26}$ IN-E8S72 and IN-WR791 are the two metabolites of it. There were no relevant reports for the residue concentration and the process of dynamic dissipation of two compounds in tomato fruits in field. Studying the deposition, uptake, and distribution dynamics of the pesticides in 
crop-environment system using dynamiCROP can be helpful to clarify the black box of pesticide-plant-environment system and reduce human exposure to the residue of famoxadone and oxathiapiprolin in tomatoes.

In this study, we defined four main goals. First, we develop an analysis method for oxathiapiprolin,

IN-E8S72, IN-WR791, and famoxadone in tomatoes and soil based on modified QuEChERS method and high performance liquid chromatography tandem mass spectrometry (HPLC-MS/MS). Second, we study the dissipation behavior of famoxadone and oxathiapiprolin in tomato fields and fit the residual pesticide concentration curves with various dissipation kinetic models thereby finding the suitable one for different combinations of pesticide-crop or environment-crop and corresponding half-lives. Third, we use dynamiCROP to simulate the pesticide dynamics in the tomato-environment systems and explain the uptake and translocation processes of famoxadone and oxathiapiprolin over time. Finally, we compare the results of experimental data with dynamiCROP simulation results and estimate the residue fraction in the harvested products and the fraction consumed by humans.

\section{MATERIALS AND METHODS}

Field Trials. The field experiments that included the dissipation and residue experiments were conducted in Beijing City in the years 2015 and 2016. The experiment date and weather conditions are shown in the Supporting Information, SI (Table S1). With respect to pesticide dissipation in tomato, there was one test treatment and one control treatment. The test treatment consisted of three parallel plots, and each plot was $30 \mathrm{~m}^{2}$. No pesticide was sprayed in the control treatment during the whole period of tomato growth.

The suspoemulsion of $330 \mathrm{~g} / \mathrm{L}$ famoxadone and oxathiapiprolin was dissolved in water and 
sprayed at active constituent level of $165 \mathrm{~g}$ a.i./ha (gram of active gradient per hectare, the recommended dosage). About $2 \mathrm{~kg}$ tomato samples and $1 \mathrm{~kg}$ soil samples were collected at random from several points in each plot at $2 \mathrm{~h}$ and 1, 2, 3, 5, 7, 10, 14, 21, 30 (only soil) and 45 (only soil) days after pesticide application. The collected samples of tomato were homogenized with a blender (Philips, China). All samples were stored in a deep freezer at below $-18^{\circ} \mathrm{C}$ until analysis.

Data Analysis. Most of the considered studies reported that dissipation trends of pesticides in plants fit to pseudo-first-order kinetics, e.g. Zhang et al., ${ }^{29}$ according to the following general equation:

$$
\mathrm{C}(\mathrm{t})=\mathrm{C}_{0} \times \mathrm{e}^{-\mathrm{kt}}
$$

where $\mathrm{C}(\mathrm{t})$ is the pesticide residue concentration $(\mathrm{mg} / \mathrm{kg})$ at the time $\mathrm{t}$ (days) between pesticide application and harvest of tomatoes, $\mathrm{C}_{0}$ is the initial concentration $(\mathrm{mg} / \mathrm{kg})$ during pesticide application time and $\mathrm{k}$ represents the constant dissipation rate coefficient $\left(\mathrm{day}^{-1}\right)$.

The corresponding half-life $\left(\mathrm{t}_{1 / 2}\right)$ of pesticides was calculated by using the following equation:

$$
\mathrm{t} 1 / 2=(\ln 2) / \mathrm{k}
$$

However, the dissipation process of pesticides in plants does not only include degradation, but also growth dilution and volatilization. ${ }^{24}$ Meanwhile, there is also uptake of pesticides from soil into plants which will lead to a negative dissipation in the crops in particular for polar compounds low octanol-water partition coefficient (Kow). ${ }^{30}$ The variability of dissipation kinetic or half-lives involves many factors, such as pesticides, plant species, sampled plant components (leaves, fruit, straw, etc.) or tissues (nectar, cuticular waxes) and environment (temperature, light/shade conditions, precipitation, etc.). ${ }^{31}$ Thus, it is not accurate that all pesticide-plant-environment combinations were fitted to first-order kinetics. Fantke and Juraske ${ }^{31}$ provide an overview of different dissipation kinetics of various pesticides in a multitude of plant species. Besides that, 
they summarized different models to fit residual pesticide concentration curves and corresponding dissipation half-lives in plants.

In the present study, we fitted the measured residual concentration data of famoxadone and oxathipiprolin in tomatoes and soil at different points in time after application to zero-order, half-order, first-order, one-and-a-half-order, second-order, root function first-order, root function one-and-a-half-order, root function second-order kinetics and combined first-first-order as mentioned by Fantke and Juraske. ${ }^{31}$ The most suitable model was identified for calculating half-life according to the fitting results.

Model data collection. In the model of dynamiCROP, which was a typical mass balance model, residual concentration of a chemical is the net result of competing uptake and elimination process. Plants uptake processes are direct application on to the plant, gaseous and dry/wet particle deposition from air onto cuticles, advective root and foliar uptake. Elimination of chemicals from plants includes volatilization, wash-off, plant growth (biodilution), and microbiological, photolysis, chemical and photodecomposition, metabolism due to oxidation and hydroxylation. ${ }^{31,32}$ To quantify these processes, multiple parameters are required as input for the models including substance properties, plant characteristics, and environmental conditions. Fantke et al. ${ }^{33}$ gave an overview about the relevant, essential, and recommended parameters for developing and improving plant accumulation models. Based on his reports, we researched the input data that our model relied on.

Substance -specific input data. Most frequently reported substance properties to be relevant for pesticide dissipation modeling are partition coefficients Kow, air-water partition coefficient (Kaw) and half-lives in plants and soil along with molar mass and application mass. Kow is a key parameter for the root uptake and subsequently translocation in xylem. The polar contaminants (low Kow) are readily 
141

142

soluble in soil pore water, taken up by roots and translocated to stems, leaves and fruits. ${ }^{30}$ For the leaves role in plant physiology, they have a very high exchange with air, and the volatile contaminants (high Kaw) will escape from leaves into air, which demonstrates the significance of Kaw for calculation of the accumulation in leaves. The degradation or total dissipation rate is a key variable and half-life $\left(\mathrm{t}_{1 / 2}\right)$ as an intuitive input parameter is relevant to dissipation kinetic or degradation rate coefficient $(\mathrm{k})$. In our study, the half-lives of famoxadone and oxathiapiprolin in tomatoes $(\mathrm{n}=10)$ and soil $(n=12)$ were derived from dissipation data obtained in the field study, which are shown in the SI (Section S4). Besides that, some other parameters (e.g. substance CAS number, IUPAC name, treat plant components, application rate and formulation) recommended by Fantke et al. ${ }^{33}$ to be applied in future testing study and kinetic models were also presented in the SI (Table S2). These data have been identified being of high relevance for developing plant bioaccumulation models.

Crop-specific input data. Tomato fruit-specific input parameters mainly related to plant lipid, water contents, growth rates, and transpiration stream. Plant lipid or water contents directly impact the transportation, partition and accumulation of polar or non-polar substances in different components. The plants with height above $40 \mathrm{~cm}$ are rarely affected by soil particle attachment through rain splashing, ${ }^{34}$ which was as a major transfer pathway for most persistent lipophilic contaminants to leaves. ${ }^{35}$ Therefore, plant height or growth rate is an important parameter for crop-specific input data. In our field experiment, the height of the tomato plants when pesticides were sprayed was about 1.3 meters. For polar contaminants, which are rapidly translocated from the bottom up, the transpiration rate is among the most important parameters, since the accumulation in leaves is most directly dependent on the transpiration, which was also demonstrated by Trapp and Pussemier. ${ }^{36}$ In this study, data for the crop-specific parameters for tomatoes simulation were taken from the studies of Fantke et 
163

164

al. ${ }^{21}$ Additional parameters are required to properly define plant species and sampled plant components or tissues (e.g. leaves, fruits or straw).$^{31}$ For example, in our experiment, the scientific crop name is Lycopersicon esculentum Mill., and the sampled matrix is tomato fruits, where residues were sampled from the whole fruit.

Environment-specific input data. Air temperature, vapor pressure, precipitation, soil pH, soil organic carbon (OC) and cation exchange capacity (CEC) are most relevant parameters for kinetic dissipation modeling along with the time between substance application and plant harvest. High temperature and vapor pressure stimulate plant physiological processes such as growth, transpiration and metabolism. ${ }^{37,38}$ Precipitation affects soil particle attachment on leaf surface, because soil particles would attach to the leaves especially when they are located close to the soil surface after rain. ${ }^{30}$ Different amounts of organic carbon in the soil can cause different degrees of adsorption of neutral compounds, thus affecting the distribution of neutral substances in soil and plant roots. ${ }^{39}$ While for the ionizable organic chemicals, some reports suggests that cation exchange capacity (CEC) of soil is a key determinant for the sorption of cations and soil organic carbon and soil $\mathrm{pH}$ are the critical factors for the sorption of anionic chemicals. ${ }^{40,41}$ Beyond that, extreme $\mathrm{pH}$ (high or low), will lead to reduced growth, and this may be accompanied by reduced uptake of contaminants. ${ }^{30}$ These parameters (SI, Table S1) were all recommended to be applied in future testing study and kinetic models. ${ }^{33}$

\section{RESULTS AND DISCUSSION}

Measured Residues of Famoxadone and Oxathiapiprolin in Tomatoes. The concentration of famoxadone and oxathiapiprolin, including IN-E8S72 and IN-WR791, were measured using the QuEChERS method and detected by HPLC-MS/MS. Sample pretreatment, HPLC-MS/MS conditions 
185

and experimental method validation are shown in the SI, Sections S1-S2. Figure 1 shows the different dissipation kinetic models of famoxadone and oxathiapiprolin in tomato samples in the years 2015 and 2016, respectively. The corresponding residual concentration curves and determination coefficient $\left(R^{2}\right)$ are showed in the SI (Table S3). According to the results, the most suitable model for two fungicides in 2015 and 2016 was first-order kinetic and second-order kinetic, respectively. For a pesticide, the difference of dissipation trend in two years may be caused by different climatic conditions and crop growth states, which also verified the conclusion of Fantke and Juraske. ${ }^{31}$

The half-lives of famoxadone and oxathiapiprolin estimated by the second-order kinetic model (best fit) are 5.2 and 3.0 days in 2016, while the ones obtained from the first-order kinetic model are 7.3 and 4.7 days, respectively. It is worth noting that half-lives derived from the best-fit model were lower than obtained using the first-order model. These results are supported by other studies, e.g. Martinez et al. ${ }^{42}$ Compared with first-order kinetics, the second-order model shows the slower diminution of residue throughout the entire dissipation process, as can be observed in Figure 1. Besides, the rate of dissipation is assumed to remain constant in the first-order model, rendering the half-life independent of initial pesticide concentrations. However, in the second-order model, degradation rate and half-life are related to the initial concentrations, with the half-life changing over time.

The initial concentrations of famoxadone in tomatoes were 0.2135 and $0.1820 \mathrm{mg} / \mathrm{kg}$ in 2015 and 2016, respectively. The initial concentrations between the two years were different, which may be caused by the different planting densities or uneven spraying in different years. The half-lives during the two years were 3.4 and 5.2 days, respectively, as calculated according to Table S3 (SI). The reason for different half-lives in two years may be that the precipitation of 2016 is slightly less than 2015 . Angioni et al. $^{43}$ determined the residue concentration of famoxadone in greenhouse tomatoes 
(Lycopersicon esculentum Mill. cv. Shiran \& Caramba) over time with half-life 8.3 days, which is longer than our experimental half-life. Except the difference of plant varieties and field locations, the primary reason for that may be less light exposure and precipitation in greenhouse. The half-lives of famoxadone in other matrix, e.g. grape, ${ }^{44,45} \operatorname{spinach}^{46}$ and watermelon leaves ${ }^{47}$ at different conditions (in or on matrix, in field or greenhouse) were also reported, the mean half-lives were 6.3-12.3d. The comparative results showed that the half-lives in fruit crops (18 days in grapes in field or 8.3 day in tomatoes in greenhouse) were longer than leaf crops (6.3 days in spinach and 9.7 days in watermelon leaves in field or 7.7 day in spinach in greenhouse), in crops (18 days in grapes in field) longer than on crops (12.3 days on grapes in field) and in greenhouse (7.7 days in spinach in greenhouse) longer than in field (6.3 days in spinach in field). Pesticides are more easily washed off by rain and loss to air through stomata in leaves, so they dissipate more quickly in leaves than in fruits. Besides, the compounds on the surface of fruit are not only easily washed off by rain, but also may be decomposed by photolysis and photo-decomposition, which results in faster degradation of the pesticide on the crop surface.

For oxathiapiprolin, the initial concentrations in our experiments were 0.0290 and $0.0178 \mathrm{mg} / \mathrm{kg}$ in 2015 and 2016, with the half-lives 2.4 and 3.0 days, respectively. Consistent with famoxadone, the half-life of 2016 was also longer than that of 2015. While for difference, the dissipation of oxathiapiprolin is quicker than famoxadone in the same condition, which was determined by substance properties. The polarity of oxathiapiprolin is stronger than famoxadone maybe caused that the former was washed off from leaf surface or fruit surface. There were no reports of oxathiapiprolin in other matrix and thus our experiment maybe provides some degradation information of it.

Modeled Residues of Famoxadone and Oxathiapiprolin in Tomatoes. The model of 
dynamiCROP was used in this work to study the mass evolution of famoxadone and oxathiapiprolin in eight main compartments [air, soil, leaf deposit (the droplet layer on the leaf surface), fruit deposit (droplet layer on the fruit surface), leaf (leaf interior), fruit (fruit interior), stem, and root] of the tomato environment system. There are three parts that showed mass evolution, which was also explained by Pang et al. ${ }^{7}$ Firstly, the diffusion and transfer of pesticides happened during the initial period. Then during the middle period, the pesticide residues reached maximum levels and subsequently decreased exponentially. In the last part, the pesticide residues degraded for the longest time.

Substance properties, plant characteristics, and environmental conditions are three main factors that influenced the dissipation of pesticide residues in plants. The first two factors were stable based on one certain pesticide and plant and could be determined by models. However, the environmental conditions were relatively complex and changeable, which became the limiting factor for modeling, including with dynamiCROP. Among the various environmental conditions, temperature ${ }^{48}$ and precipitation ${ }^{7}$ were considered as the main factors influencing pesticide dissipation trends or half-lives for dynamiCROP. In our work, the average temperature and precipitation during the periods of planting in 2015 and 2016 was not much different (see SI, Table S1). Table S2 (SI) shows the data for $t_{1 / 2}$ tomatoes and $t_{1 / 2}$ for soil, where the crop degradation rate coefficient and soil degradation rate coefficient are two influential input parameters for the model, which was evaluated by Fantke et al. ${ }^{8}$ Their study showed that the crop degradation rate is one of the 10 input parameters, for which model output varies the most across pesticides and crops. In contrast, soil degradation was shown to be a driving parameter only for root and tuber crops (e.g. potato), but not for other crops. This is consistent with our results, where the influence of soil degradation is of minor influence for model output for tomato. Based on that finding, we chose the result of one year (2015) for further analysis. 

compartments, the residue residence time was less than $1 \mathrm{~d}$ (see Table 1). Famoxadone started to appear in root and stem parts in $0.1 \mathrm{~d}$ and $3 \mathrm{~d}$, respectively. While for oxathiapiprolin, the pesticide only reached at the air, soil, leaf surface, and fruit surface during the initial term. Thereafter, its mass quickly decreased in the air and leaf surface with the residence time of $0.0099 \mathrm{~d}$ and $0.172 \mathrm{~d}$, respectively. To the contrary, in compartments of leaf, fruit, root, and stem, the mass of the pesticide gradually increased. These results showed that pesticides quickly transferred between different compartments after application and the transfer routes were vary depended on different pesticides properties. During the middle period, pesticide mass in leaf, fruit, stem, and root compartments reached maximum values. For famoxadone, maximum mass ranged from $8.5 \times 10^{-6} \mathrm{~kg} / \mathrm{m}^{2}$ in leaf after $0.3 \mathrm{~d}$ to $2.1 \times 10^{-7} \mathrm{~kg} / \mathrm{m}^{2}$ in stem after $17 \mathrm{~d}$. For oxathiapiprolin, the maximum mass ranged from $7.5 \times 10^{-7} \mathrm{~kg} / \mathrm{m}^{2}$ in leaf after $1 \mathrm{~d}$ to $2.9 \times 10^{-8} \mathrm{~kg} / \mathrm{m}^{2}$ in root after $3 \mathrm{~d}$. Then the mass of the pesticide decreased exponentially until harvest. There were various reasons for the decrease of pesticide residue, we have explained above. pesticides in all compartments continued to decrease, and the overall system dynamics is driven by a single compartment with the highest residual mass, namely both leaf for famoxadone and oxathiapiprolin, which corresponds to the longest overall residence time in Table 1. 

we refer to Fantke et al. ${ }^{31}$

measured residues for both famoxadone and oxathiapiprolin in 2015 was relatively large, which may be caused by other unconsidered weather conditions (e.g. air humidity or sunlight intensity). 
295

physico-chemical properties and the applied quantities were the two factors used for modeling the evolution of pesticide residues. ${ }^{9}$ However, for the low final concentrations of the residues of the two pesticides, there was no much difference between the harvest fractions of famoxadone and oxathiapiprolin.

Modeled intake fractions, i.e., the fractions of applied pesticide masses that are potentially ingested through crop consumption, were $3.5 \times 10^{-3} \mathrm{~kg}_{\text {intake }} \mathrm{kg}_{\text {applied }}{ }^{-1}$ for famoxadone and $3.7 \times 10^{-3}$ $\mathrm{kg}_{\text {intake }} \mathrm{kg}_{\text {applied }}{ }^{-1}$ for oxathiapiprolin, which were accounted for by the food processing factor of 0.47 for washing. Variability in intake fractions mainly depended on residue degradation in crops, apart from food processing. For tomato, human intake fractions across pesticides usually vary between 1 $\mu \mathrm{g}_{\text {intake }} / \mathrm{kg}_{\text {napplied }}$ and $10 \mathrm{~g}_{\text {intake }} / \mathrm{kg}_{\text {applied. }}{ }^{14,21}$ Our results fall well within this range.

Supporting Information. Brief statement in nonsentence format listing the contents of the material supplied as Supporting Information.

\section{Notes}

The authors declare no competing financial interest.

\section{REFERENCES}

(1) FAOSTAT. The FAO (Food and Agriculture Organization of the United Nations) Compare Data. 
(2) Kong, Z.; Dong, F.; Xu, J.; Liu, X.; Zhang, C.; Li, J.; Li, Y.; Chen, X.; Shan, W.; Zheng, Y.

(3) Meher, H.C.; Gajbhiye, V.T.; Singh, G.; Kamra, A.; Chawla, G. Persistence and Nematicidal Chem. 2018, 66, 1701-1713.

(6) Xu, M.; Gao, Y.; Han, X. X.; Zhao, B. Detection of Pesticide Residues in Food Using Surface-Enhanced Raman Spectroscopy: A Review. J. Agric. Food Chem. 2017, 65, 6719-6726.

(7) Pang, N.; Cui, Y.; Hu, J. Weather dependent dynamics of the herbicides florasulam, carfentrazone-ethyl, fluroxypyr-meptyl and fluroxypyr in wheat fields through field studies and computational simulation. Chemosphere. 2016, 165, 320-328.

(8) Fantke, P.; Wieland, P.; Juraske, R.; Shaddick, G.; Itoiz, E. S.; Friedrich, R.; Jolliet, O. Parameterization models for pesticide exposure via crop consumption. Environ. Sci. Technol. 2012, 46, 12864-12872.

(9) Li, L.; Jiang, G.; Liu, C.; Liang, H.; Sun, D.; Li, W. Clothianidin dissipation in tomato and soil, and distribution in tomato peel and flesh. Food Control. 2012, 25, 265-269. 
(10) Chauhan, R.; Monga, S.; Kumari, B. Dissipation and decontamination of bifenthrin residues in tomato ( Lycopersicon esculentum Mill). B. Environ. Contam. Tox. 2012, 89, 181-186.

(11) Feng, X.; Yu, J.; Pan, L.; Song, G.; Zhang, H. Dissipation and residues of dichlorprop-p and bentazone in wheat-field ecosystem. Inter J Env Res Pub Heal. 2016, 13, 534-547.

(12) Wang, X.; Zhang, H.; Xu, H.; Wang, X.; Wu, C.; Yang, H.; Li, Z.; Wang, Q. Enantioselective residue dissipation of hexaconazole in cucumber (Cucumis sativus L.), head cabbage (Brassica oleracea L. var. caulorapa DC.), and soils. J. Agric. Food Chem. 2012, 60, 2212-2218.

(13) You, X.; Liang, L.; Liu, F. Dissipation and residues of clethodim and its oxidation metabolites in a rape-field ecosystem using QuEChERS and liquid chromatography/tandem mass spectrometry. Food Chem. 2014, 143,170-174.

(14) Juraske, R.; Antón, A.; Castells, F.; Huijbregts, M. A. Human intake fractions of pesticides via greenhouse tomato consumption: comparing model estimates with measurements for Captan. Chemosphere. 2007, 67, 1102-1107.

(15) Fantke, P.; Charles, R.; Alencastro, L. F. D.; Friedrich, R.; Jolliet, O. Plant uptake of pesticides and human health: Dynamic modeling of residues in wheat and ingestion intake. Chemosphere. 2011, 85, 1639-1647.

(16) Trapp, S. Fruit Tree model for uptake of organic compounds from soil and air. Sar Qsar Environ. Res. 2007, 18, 367-387

(17) Trapp, S.; Cammarano, A.; Capri, E.; Reichenberg, F.; Mayer, P. Diffusion of PAH in potato and carrot slices and application for a potato model. Environ. Sci. Technol. 2007, 41, 3103-3108.

(18) Charles, R. Modelling Pesticides Residues. Thesis no. 3123, Ecóle Polytechnique Fédérale de Lausanne, Switzerland. 2004. <library.epfl.ch/theses/?nr=3123>. 
361

362

363

364

365

366

367

368

369

370

371

372

373

(19) Rein, A.; Legind, C. N.; Trapp, S. New concepts for dynamic plant uptake models. Sar Qsar Environ. Res. 2011, 22, 191-215.

(20) Legind, C. N.; Kennedy, C. M.; Rein, A.; Snyder, N.; Trapp, S. Dynamic plant uptake model applied for drip irrigation of an insecticide to pepper fruit plants. Pest Manag. Sci. 2011, 67, $521-527$.

(21) Fantke, P.; Juraske, R.; Antón, A.; Friedrich, R.; Jolliet, O. Dynamic multicrop model to characterize impacts of pesticides in food. Environ. Sci. Technol. 2011, 45, 8842-8849.

(22) Juraske, R.; Fantke, P.; Ramírez, A. C.; González, A. Pesticide residue dynamics in passion fruits: comparing field trial and modeling results. Chemosphere. 2012, 89, 850-855.

(23) Itoiz, E. S.; Fantke, P.; Juraske, R.; Kounina, A.; Vallejo, A. A. Deposition and residues of azoxystrobin and imidacloprid on greenhouse lettuce with implications for human consumption. Chemosphere. 2012, 89, 1034-1041.

(24) Jacobsen, R. E.; Fantke, P.; Trapp, S. Analysing half-lives for pesticide dissipation in plants. SAR. QSAR. Environ. R. 2015, 26, 325-342.

(25) Fantke, P.; Jolliet, O. Life cycle human health impacts of 875 pesticides. Int. J. Life Cycle Ass. 2016, 21, 722-733.

(26) Wu, X.; Xu, J.; Dong, F.; Liu, X.; Li, Y.; Zheng, Y. Simultaneous determination of oxathiapiprolin and two metabolites in fruits, vegetables and cereal using a modified quick, easy, cheap, effective, rugged, and safe method and liquid chromatography coupled to tandem mass spectrometry. J. Chromatogr. A. 2014, 1329, 30-37.

(27) Ji, P.; Csinos, A. S. Effect of oxathiapiprolin on asexual life stages of Phytophthora capsici and disease development on vegetables. Ann. Appl. Biol. 2015, 166, 229-235. 
383

384

385

386

387

388

389

390

391

392

393

394

395

(28) Angioni, A.; Porcu, L.; Dedola, F. Determination of famoxadone, fenamidone, fenhexamid and iprodione residues in greenhouse tomatoes. Pest Manag. Sci. 2012, 68, 543-547.

(29) Zhang, X.; Shen, Y.; Yu, X. Y.; Liu, X. J. Dissipation of chlorpyrifos and residue analysis in rice, soil and water under paddy field conditions. Ecotox. Environ. Saf. 2012, 78, 276-280.

(30) Trapp, S.; Legind, C. N. Uptake of Organic Contaminants from Soil into Vegetables and Fruits. In Dealing with Contaminated Sites, Swartjes, F., Eds.; Springer: Dordrecht, Netherlands, 2011; $369-408$.

(31) Fantke, P.; Juraske, R. Variability of pesticide dissipation half-lives in plants. Environ. Sci. Techno. 2013, 47, 3548-3562.

(32) Collins, C.D.; Martin, I.; Doucette, W. Plant uptake of xenobiotics. In Organic Xenobiotics and Plants. Plant Ecophysiology, Schröder, P.; Collins, C., Eds.; Springer: Dordrecht, Netherlands, $2011 ; 8,3-16$.

(33) Fantke, P.; Arnot, J. A.; Doucette, W. J. Improving plant bioaccumulation science through consistent reporting of experimental data. J. Environ. Manage. 2016, 181, 374-384.

(34) Li, J. G.; Gerzabek, M. H.; Muck, K. An experimental study on mass loading of soil particles on plant surfaces. Bodenkultur. 1994, 45, 15-24.

(35) Mikes, O.; Cupr, P.; Trapp, S; Klanova, J. Uptake of polychlorinated biphenyls and organochlorine pesticides from soil and air into radishes (Raphanus sativus). Environ Pollut. 2009, 157, 488-496.

(36) Felizeter, S.; Mclachlan, M. S.; Voogt, P. D. Root Uptake and Translocation of Perfluorinated Alkyl Acids by Three Hydroponically Grown Crops. J. Agric. Food Chem. 2014, 62, 3334-3342.

(37) Yu, X.; Trapp, S.; Zhou, P.; Hu, H. The effect of temperature on the rate of cyanide metabolism 
of two woody plants. Chemosphere. 2005, 59, 1099-1104.

406

407

408

409

(38) Yu, X. Z.; Trapp, S.; Zhou, P. H.; Chen, L. Effect of Temperature on the Uptake and Metabolism of Cyanide by Weeping Willows. Int. J. Phytoremediation. 2007, 9, 243-255.

(39) Cox, L.; Fernandes, M. C.; Zsolnay, A.; Hermosã-N, M.C.; Cornejo, J. Changes in dissolved organic carbon of soil amendments with aging: effect on pesticide adsorption behavior. J. Agric. Food Chem. 2004, 52, 5635-5642.

(40) Droge, S. T.; Goss. K, U. Sorption of organic cations to phyllosilicate clay minerals: CEC-normalization, salt dependency, and the role of electrostatic and hydrophobic effects. Environ. Sci. Techno. 2013, 47, 14224-14232.

(41) And, M. K.; Brown, C. D. Prediction of the Adsorption of Ionizable Pesticides in Soils. J. Agr. Food Chem. 2007, 55, 2312-2322.

(42) Martinez, G. M.; Gil Garcia, M. D.; Rodriguez Lallena, J. A.; Lopez, L. T.; Martinez Vidal, J. L. Dissipation of pyrethroid residues in peppers, zucchinis, and green beans exposed to field treatments in greenhouses: evaluation by decline curves. J. Agric. Food Chem. 2003, 51, $5745-5751$.

(43) Angioni, A.; Porcu, L.; Dedola, F. Determination of famoxadone, fenamidone, fenhexamid and iprodione residues in greenhouse tomatoes. Pest Manag. Sci. 2012, 68, 543-547.

(44) Scaranelo, A. M.; Crystal, P.; Bukhanov, K.; Helbich, T. H. Residues of the fungicide famoxadone in grapes and its fate during wine production. Food Addit Contam. 2006, 23, 289-94.

(45) Jing, G.; Qin, D.; Zhao, Y.; Pan, C.; Jiang, S.; Liu, F. Dissipation and residue of famoxadone in grape and soil. Environ Monit Assess. 2010, 162, 219-224.

(46) Qian, M.; Wu, L.; Zhang, H.; Wang, J.; Li, R.; Wang, X.; et al. Stereoselective determination of 

spinach. J. Sep. Sci. 2011, 34, 1236-1243.

429 (47) Liu, C.; Qin, D.; Zhao, Y.; Pan, C.; Jiang, S.; Liu, F. Famoxadone residue and dissipation in watermelon and soil. Ecotox Environ Saf. 2010, 73, 183-188. 
435 Figure 1. Different dissipation kinetic models for famoxadone and oxathiapiprolin during the 436 years of 2015 and 2016 in tomato samples in Beijing, respectively (The most suitable model was 437 expressed with solid line and others dotted lines)

438 Figure 2. The modeled mass evolution of famoxadone and oxathiapiprolin in eight main compartments of the tomato ecosystem

440 Figure 3. Modeled versus measured residue concentrations $(\mathrm{mg} / \mathrm{kg})$ of famoxadone and 441 oxathiapiprolin in tomatoes at time $\mathrm{t}=0,1,2,3,5,7,10,14$ and $21 \mathrm{~d}$ after the pesticide application 442 in 2015 and 2016 
445 TABLES

446 Table 1. Modeled parameters of famoxadone and oxathiapiprolin in tomato

\begin{tabular}{|c|c|c|c|}
\hline Parameters & & famoxadone & oxathiapiprolin \\
\hline Residence Times in & air & 0.203 & 0.099 \\
\hline \multicolumn{4}{|l|}{ Compartments (day) } \\
\hline & soil & 13.287 & 7.242 \\
\hline & Leafsurf. & 0.079 & 0.172 \\
\hline & Fruitsurf. & 0.094 & 4.115 \\
\hline & leaf & 13.579 & 8.132 \\
\hline & fruit & 13.573 & 4.468 \\
\hline & stem & 8.659 & 3.144 \\
\hline & root & 5.733 & 1.256 \\
\hline \multirow[t]{4}{*}{ Time of maximum mass (day) } & $\mathrm{T}_{\text {max,leaf }}$ & 0.3 & 1 \\
\hline & $\mathrm{T}_{\text {max,fruit }}$ & 0.3 & 1 \\
\hline & $\mathrm{T}_{\text {max,stem }}$ & 17.0 & 6 \\
\hline & $\mathrm{T}_{\text {max,root }}$ & 8.0 & 3 \\
\hline Residue at maximum time & fruit & 0.038 & 0.015 \\
\hline
\end{tabular}



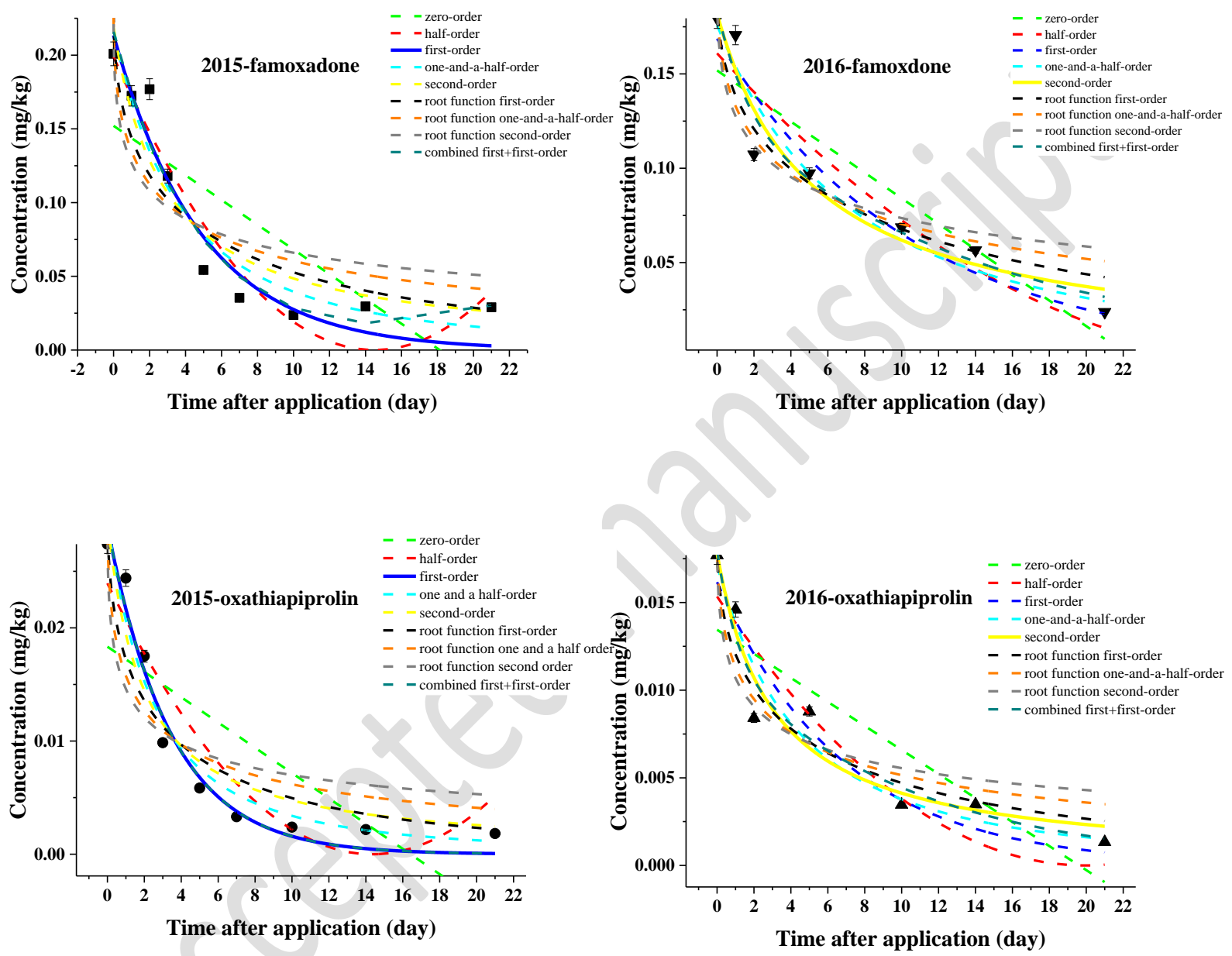
Figure.2
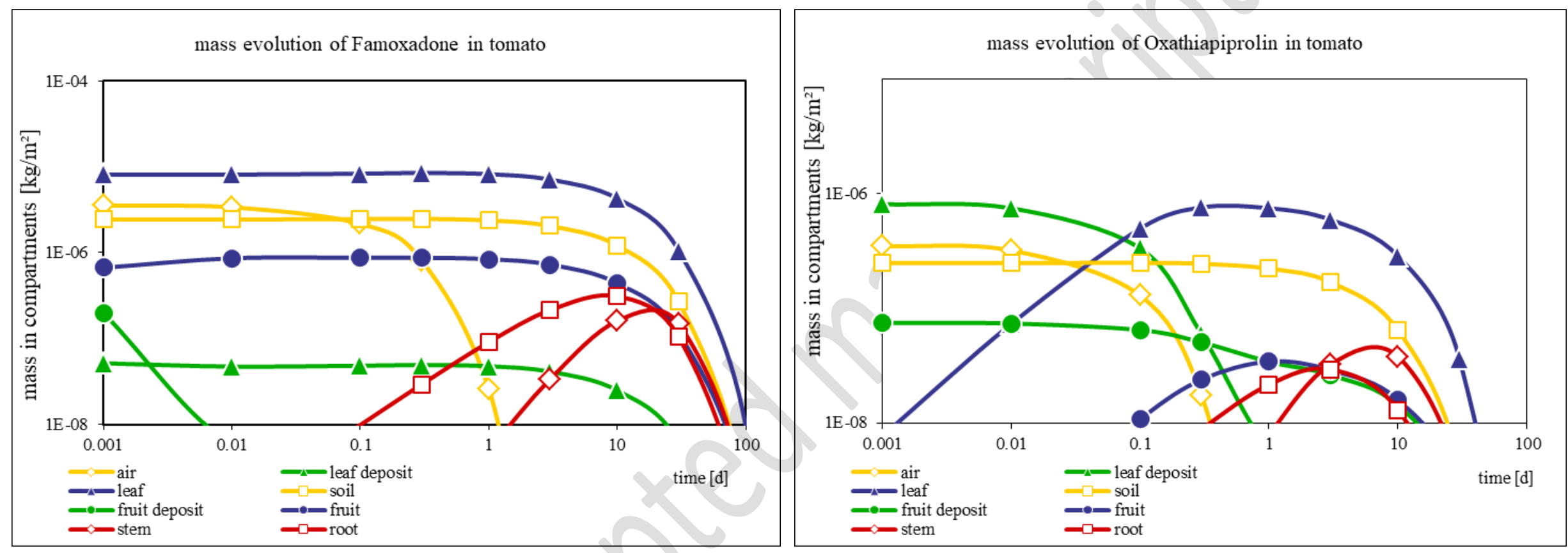
Figure. 3

2
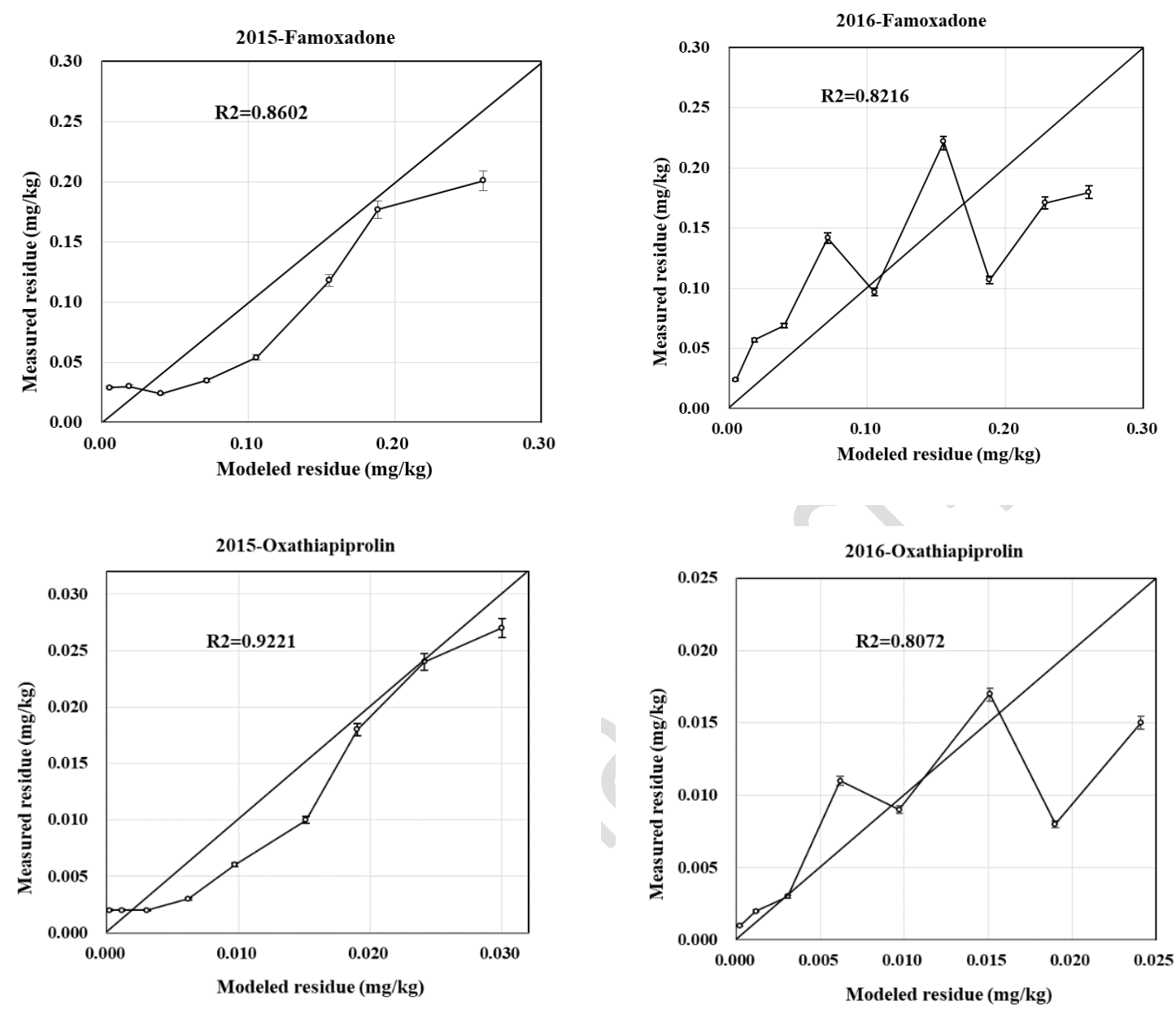

3 


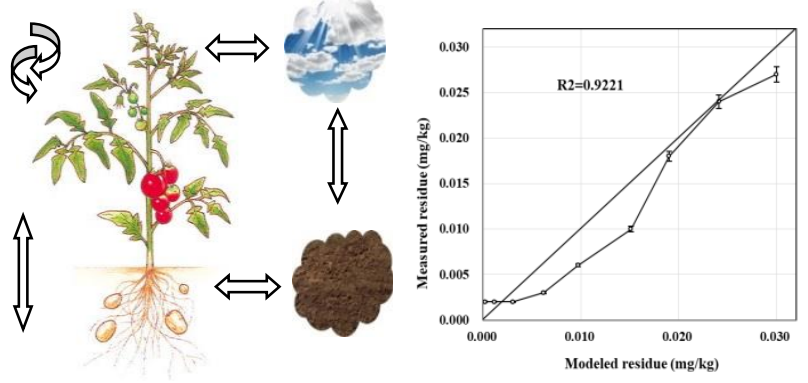

Field experiment vs Model estimation Evaluating results 